\title{
Editorial \\ Reeling and Writhing - An Exploration of Intertextuality
}

Shreya Sridharan, University of Warwick

I warmly welcome you to Reinvention's latest special edition, one I am very proud to introduce as the first in my position as Editor. We bring to you an amalgamation of incisive research and imaginative poetry in our showcase of student work from a module in the University of Warwick's Writing Programme named Reeling and Writhing. Although perhaps not immediately obvious, this issue brings forth a new kind of interdisciplinarity as the students analyse literature and media by engaging with history, philosophy and sociology, all within the context of creative writing.

Reeling and Writhing, as a module, focused on teaching students that the creation and reception of texts cannot be separated from cultural contexts and societal responses to religion, history and myth. As outlined in our guest article, students were taught about myths and retellings of stories, as well as the strategies and means through which mythologies are created. Finally, they were tasked with creating poetry using intertextuality, which we now display in this issue. The cover, created by Elle Pearson, captures the relationship between the modern and the mythological as seen in our world - something that is explored in detail within this issue.

What can we as an audience learn from their work? How can we ourselves learn about intertextuality?

Intertextuality, in simple terms, refers to how one text can shape the meaning of another, and also refers to the connection between such related texts that can influence an audience's interpretation of the work. The papers in this issue focus on intertextuality and explore key themes or depictions or characters that tie different works together, across centuries and creators. We are not limited to literature, but rather focus on how different media - be it film or even games - are created and situated within their societal contexts, and how previous iterations affect this creation. 
I believe that intertextuality can be considered a cornerstone of Reinvention, given our focus on interdisciplinarity. In our publications, we strive to showcase work that approaches a problem from different perspectives and, in doing so, we can highlight how different subjects influence each other. For example, in our recent issues, we have published work on climate change with one article from a meteorological view and one from a sustainable development view. As an audience, we are likely to embed contrasting and complementary ideas from these disciplines into our understanding of climate change, and I argue that this kind of receptive reading is one form of intertextuality.

When considering the content for this issue, what stood out to me (besides my personal interest in the works discussed) is how accessible it is. The pieces include not only literary classics such as The Iliad and Shakespeare's writing but also more recent work such as Twilight, The Song of Achilles and Jennifer's Body. These works are commonplace and, even if a typical reader has not considered their own perception of them, they are likely to have come across them. I think this is a special feature of this issue, which makes it an exciting read. A common theme tying the papers together is the evolution of ideas and intergenerational links - how have depictions of characters changed and why? What influences this? I think the analyses presented here give us much to learn, even as laypeople, about our own consumption of media - teaching us to reflect and rediscover what any art says and what brought it there.

Another special feature of this issue is the poetry that accompanies the research, as this is the first time Reinvention has published creative writing. The poems featured here cover a wide range of themes, from explorations of gender and sexuality to retellings of myths and to themes of horror and violence. They capture some of the central ideas of the papers and do so by subverting expectations - in theme, style and form. I welcome our readers to listen to these voices carefully and experience the visceral as they read the poems.

This issue begins with a guest article, co-written by Giulia Champion and some of the student contributors - Alba Alonso Palombi, Estelle Wallis and Italo Ferrante. It outlines the idea and conception of this issue and what we hope our readers can take away from it. As Estelle aptly points out, poetry as a medium is personal, and our contributors have written 
beautiful, moving and personal poetry that reinterprets and recontextualises many of the texts discussed. I hope that this allows our readers to consider these texts in a new light and to reflect on how and in what ways different media can contribute to intertextuality.

In 'Crosses to Cullens: The Western Vampire from Gothic Predator to Romantic Icon', Alex Fewings examines how the depictions of sexuality in vampires have evolved from early Gothic fiction to modern portrayals of vampires. He places the figure of the vampire within the context of modern romance, rather than horror, and expertly weaves together this evolution of the character with questions of sexual acceptance and gender in the West.

Alba Alonso Palombi's 'The New Femme Fatale in Jennifer's Body focuses on the character of Jennifer Check from the Diablo Cody film Jennifer's Body, examining how she relates to the trope of the femme fatale. In doing so, the paper offers a contextualised history of the femme fatale, from biblical figures to more recent characters, and posits that a new and empowered femme fatale has arrived - one who uses her power against those who have abused her.

In 'A Creature Without a Cave: Abstraction and (Mis)Appropriation of the Wendigo Myth in Contemporary North American Horror', Francesca Johnson analyses the representation of the Wendigo myth in North American horror across the media of television, film and games. She highlights how the use of the Wendigo by non-Indigenous creators can lead to problematic depictions of Indigenous culture and calls for a focus on Indigenous voices in the discourse on caveless creatures.

Estelle Wallis's 'The Once and Future Story: Arthurian Mythology as an Emblem for Western Ideals' explores three key texts in Arthurian literature to show how authors use the Arthurian myth to promulgate their society's values and priorities. Her paper provides a masterful analysis of how the myth is both influenced by and influences the Western psyche and is extremely relevant in an age where new forms of democratised media are used to shape societal values.

In 'The Relationship Between History and Mythology in Sondheim and Weidman's Assassins', Kirsten Scheiby investigates how historical narratives are intertwined with mythology and offers an alternative view of 
the myth of assassins. She convincingly argues that the Sondheim/Weidman musical repositions assassins as three-dimensional people who are pursuing and participating in cultural ideals in contrast to previous representations of assassins as caricatured madmen. She offers an interesting insight into how historical figures are created by mythology and, in turn, how they can subsequently perpetuate mythologies.

Finally, J. S. Campion's 'Examining Patroclus' role in The Iliad, Troilus and Cressida and The Song of Achilles' investigates how the character of Patroclus affects the depictions of Achilles and is used to develop themes of war. The paper employs a queer reading of the relationship between Patroclus and Achilles in the three aforementioned texts to emphasise its influence on the representation of war and its use in conveying the authors' attitudes towards war.

This issue, while focused on creative writing and literature, brings forth a new kind of interdisciplinarity, and I hope these papers and poetry resonate with our readers. It is a positive and key step for our readers to start thinking about creative practice as a research activity, and I welcome our readers to explore newer avenues of research. I would like to thank Giulia Champion for reaching out and proposing this special issue of Reinvention and for all her work. I also thank and congratulate all contributing authors. At Reinvention, we are always open to engaging with new projects, and we welcome any ideas for further special issues. Finally, I encourage our readers to look out for our April issue and to continue to engage with Reinvention in any way that they can.

To cite this paper please use the following details: Sridharan, S. (2022), 'Reeling and Writhing - An Exploration of Intertextuality', Reinvention: an International Journal of Undergraduate Research, Special Issue | Reeling and Writhing: Intertextuality and Myth, https://reinventionjournal.org/article/view/1100. Date accessed [insert date]. If you cite this article or use it in any teaching or other related activities please let us know by e-mailing us at Reinventionjournal@warwick.ac.uk. 